DOI 10.37882/2223-2982.2021.10.12

\title{
ГРАММАТИЧЕСКИЕ ОСОБЕННОСТИ ВЫРАЖЕНИЯ ВЕЖЛИВОСТИ В АНГЛИЙСКОМ ЯЗЫКЕ
}

\section{GRAMMATICAL FEATURES OF POLITENESS AS LINGUISTIC CATEGORY IN THE ENGLISH LANGUAGE}

\author{
O. Vendina \\ A. Tkachenko \\ I. Fileshi
}

Summary: This article is devoted to the study of the grammatical features of politeness as speech act in English. The authors of the article analyze the morphological and syntactic means of speech by which the polite utterances are being created. Taking as a basis the speech act of request the authors of the article identify the grammatical features of the communicative strategies of politeness. They define the concept of politeness according to the theory of speech acts, reveal the specific features of the politeness as a linguistic and national phenomenon, identify the grammatical (morphological and syntactic) constructs of politeness in the English language.

Keywords: category of politeness, national mentality, speech act, communicative behavior.

\author{
Вендина Оксана Владимировна \\ К.п.н., ФГАОУ ВО «Северо-Кавказский \\ федеральный университет» \\ oksya100@mail.ru \\ Ткаченко Анастасия Евгеньевна \\ К.полит.н., ФГАОУВО «Северо-Кавказский \\ федеральный университет» \\ anastasiiatkachenko@mail.ru \\ Филеши Ирина Владимировна \\ К.п.н., ФГАОУВО «Северо-Кавказский \\ федеральный университет» \\ ir.mishencko@mail.ru
}

Аннотация: Данная статья посвящена изучению грамматических особенностей речевого акта вежливости в современном английском языке, а именно анализу морфологических и синтаксических средств, посредством которых создаются вежливые высказывания. На примере речевого акта просьбы авторы статьи выявляют грамматические особенности коммуникативных стратегий, обеспечивающих успешное общение, в котором вежливости отводится особое место. Авторы статьи раскрывают понятие вежливости с позиции теории речевых актов, определяют специфику речевого акта вежливости как лингвистического и национального феномена, выявляют грамматические (морфологические и синтаксические) средства реализации стратегии вежливости в английском языке.

Ключевые слова: категория вежливости, национальный менталитет, речевой акт, коммуникативное поведение.

ных отношений, привлекающую такое пристальное внимание ученых. Как отмечает Ричард Уоттс, к началу XXI века было опубликовано около 1200 работ, связанных с данной темой [7, с. хі]. Существует даже специализированный журнал - "Journal of Politeness", в котором, начиная с 2005 года, было опубликовано около 130 статей, посвященных самым различным аспектам исследования категории вежливости.

Исследования вежливости отличаются междисциплинарным характером, т.к. они ведутся на пересечении лингвопрагматики и социолингвистики, речеведения и методики преподавания иностранных языков, психологии, социологии и социальной антропологии, культурологии и гендерных исследований [5, с. 2]. Но вежливость - это не только социокультурное явление. Это еще и лингвистическая категория, структура которой представлена на вербальном уровне.

Начало изучения вежливости в лингвистике связывается с исследова-ниями английских и американских лингвистов второй половины XX века, талких как П. Браун и С. Левинсон, Р. Лакофф, Дж. Лич, Е. Гофман, П. Грайс и 
другие. Данные ученые говорят о вежливости как об особой категории речевого общения, которая, представляя собой обобщенную коммуникативно-прагматическую единицу, участвующую в организации и регулировании взаимоотношений между коммуникантами, имеет определенную структуру, собственное коммуникативное содержание и языковые средства выражения.

Вежливость как определенная стратегия коммуникативного поведения связана с прагматической теорией речевого общения. Поэтому исследование вежливости как лингвистической категории вышло из теории речевых актов. Под речевым актом понимается «целенаправленное речевое действие, совершаемое в соответствии с принципами и правилами коммуникативного поведения, принятыми в каждом данном обществе» [4, с. 23]. По Дж. Остину, выполнить речевой акт - значит построить высказывание из слов данного языка по правилам грамматики, снабдить высказывание смыслом и референцией, то есть соотнести с действительностью, придать ему речевую целенаправленность и воздействовать на сознание и поведение адресата [4, с. 25].

Как отмечает Е.Л. Ерзинкян, в содержательном плане категория вежливости служит для передачи семантики уважительности и почтения к собеседнику. Но в плане выражения эта категория характеризуется набором языковых форм, которые в совокупности определяют специфику данной категории. В качестве вежливых могут использоваться средства разных языковых уровней: фонетические (интонация и просодика), лексико-семантические, морфологические, синтаксические [2, с. 122]. В данной статье мы рассмотрим возможный и допустимый репертуар морфологических и синтаксических средств современного английского языка, имеющийся в распоряжении говорящего для создания речевых актов вежливости применительно к различным ситуациям общения.

Категория вежливости включает большое количество речевых актов: утверждение, приказ, требование, просьба, совет, предложение, приглашение, обещание, убеждение и т.п. Учитывая ограниченность объема данной статьи, мы решили остановиться на специфике грамматической организации только одного речевого акта просьбы.

Просьба - это «побудительный речевой акт, предполагающий действие, совершаемое слушающим в интересах говорящего, при этом у исполнителя действия есть свобода выбора относительно того, совершать это действие или нет» [3, с. 212]. Т.В. Ларина считает просьбу опасным речевым актом, поскольку она «содержит угрозу для обоих участников коммуникации: угрозу для объекта, на свободу которого покушаются, и угрозу для самого субъекта, который может получит отказ» [3, с. 213]. В связи с этим участник коммуникации при изложении своей просьбы другому участнику коммуникации дол- жен соблюдать принцип вежливости, чтобы случайно не обидеть своего собеседника, не быть слишком навязчивым. С другой же стороны, попросив о чем-то своего собеседника, он может побудить адресата к действию, хотя последний может его не совершать, нарушив тем самым волеизъявление говорящего. Этот факт приводит к тому, что при реализации речевого акта просьбы коммуниканты наиболее активно используют стратегии дистанцирования, которая предполагает использование целого ряда как лексических, так и грамматических средств.

Просьба может быть выражена как прямо, так и косвенно. Англичане отдают предпочтение косвенному способу. Однако, и прямой способ возможен.

При прямом способе просьба может выражаться посредством императива, т.е. повелительного наклонения. Например:

"Please forget the words I said, which have no application whatever to you." (Conan Doyle A. 'The Hound of the Baskervilles') [6].

Императив в данном примере усилен модификатором - частицей please.

При выражении просьбы могут использовать и декларативные высказывания, которые могут быть представлены конструкцией Complex Object:

"I know that James didn't do it. I know it, and I want you to start upon your work knowing it, too" (Conan Doyle A. 'The Boscombe Valley Mystery') [6].

Однако, роль императива и декларативов в выражении просьбы незначительна. Подобные конструкции характерны для низкого уровня вежливости, который фигурирует в процессе неформального общения (среди друзей, членов семьи). Эти формы просьбы не оставляют человеку выбора, он не имеет права не совершать действие, «назначенное» ему собеседником. Добавление модификаторов (таких, как please) не смягчает просьбы. Эффект смягчения побуждения достигается только в комбинации please с другими средствами. Отрицательные императивные конструкции типа "Don't move, I beg you, Watson" (Conan Doyle A. 'The Hound of the Baskervilles') [6], несмотря на модификатор / beg уои, также отличаются пониженной степенью вежливости.

Прямые декларативные высказывания, выражающие просьбу типа "I want you to take it home with you, and to mark off all the hardware sellers, with their addresses" (Conan Doyle A. 'The Stock-broker's Clerk') [6] тоже не типичны для английской коммуникативной культуры. По прямолинейности в восприятии англичан они очень близки императивным высказываниям, поскольку в них говорящий также прямо сообщает о своем желании, не принимая в расчет желание собеседника, тем самым демонстрируя свое превосходство. Чтобы избежать этого, 
используются такие средства смягчения побуждения:

- сослагательное наклонение: "I'd like to give them a complete case when they come." (Conan Doyle A. 'The Stock-broker's Clerk') [6];

- прошедшее время: "I wanted to say to you how sorry I am about the stupid mistake I made in thinking that you were Sir Henry" (Conan Doyle A. 'The Hound of the Baskervilles') [6].

Эти средства относятся к косвенным способам выражения просьбы в вежливой форме, которым отдается предпочтение в английской коммуникации. Вежливость косвенных высказываний объясняется тем, что они облегчают слушающему возможность отказа, предоставляют возможность не совершать действие, к которому его побуждают. Но главное, они демонстрируют уважение говорящего к независимости адресата, поскольку звучат не как прямое побуждение к действию, а как вопрос о возможности или желании адресата это действие совершить, т.е. последнее слово собеседника остается за ним.

Наиболее распространенным способом выражения просьбы являются вопросительные высказывания с модальными глаголами в условном, или сослагательном, наклонении, которое обычно представляет события как гипотетические, т.е. не существующие в действительности. Глагол в сослагательном наклонении увеличивает степень вежливости высказывания, поскольку это наклонение выражает предположительность, гипотетичность со стороны говорящего, которая отсутствует в глаголах в индикативном наклонении, и таким образом снижает прямолинейность высказывания. Адресату предоставляется возможность выбора, а говорящий при этом выражает долю сомнения в возможности или желании адресата совершить действие.

Среди вопросительных высказываний в сослагательном наклонении выделяются два основных типа:

1. Объектно-ориентированные, т.е. ориентированные на слушающего: "Can you tell the position of the rooms?" (Conan Doyle A. 'The Hound of the Baskervilles') [6];

2. субъектно-ориентированные, т.е. ориентированные на говорящего:

"Can I be of assistance (Conan Doyle A.'The Adventure of the Speckled Band') [6].

Среди вопросов первой группы можно выделить вопросы о возможности адресата совершить действие (can you, could you) и вопросы о его намерении и желании (will you, would you). Вопросы о возможности наиболее употребительны на всех уровнях вежливости. При этом высказывания с глаголами could и would звучат более мягко, чем с can и will. Они выступают в качестве дистанцирующих средств и позволяют избежать прямолинейности высказывания, в результате чего уменьшается степень воздействия на адресата:
"Could you swear to that man's face within the cab?" (Conan Doyle A. 'The Hound of the Baskervilles') [6].

Следует обратить внимание на то, что в английском языке, наряду с вопросительно-утвердительными высказываниями, часто используются вопросительноотрицательные высказывания, хотя существует точка зрения, что более вежливыми все же считаются вопросительно-утвердительные высказывания, поскольку в вопросительно-отрицательных высказываниях содержится большее побуждение дать некоторый упрек в адрес слушающего:

"Couldn't you come any other time?"(Conan Doyle A. 'The Adventure of Charles Augustus Milverton') [6].

Однако, все зависит от ситуации. Степень вежливости вопросительно-отрицательных высказываний будет определяться в каждом конкретном случае, исходя как из широкого, так и узкого контекста. Отрицательно-вопросительная форма просьбы обладает большой побудительной силой и употребляется в ситуации, где отсутствует готовность адресата выполнить каузируемое действие. Она предполагает только положительную реакцию на вопрос, поэтому и является менее вежливой, чем утвердительная форма. Так, конструкция Won't уои $+V$ является весьма вежливой, поскольку заставляет адресата совершить, как правило, нежелаемое для него действие:

"Won't you tell us what has happened?" (Conan Doyle A. 'The Naval Treaty') [6].

Вопросительные высказывания могут быть ориентированы и на самого говорящего:

"How could I search for it without the French police having their suspicions aroused?" (Conan Doyle A. 'The Adventure of the Second Stain') [6].

В этом случае они всегда являются более вежливыми, чем вопросы, направленные на собеседника.

Вопросы с глаголом will также являются достаточно распространенным способом выражения просьбы, но, в зависимости от ситуации, они могут звучат с большей ли меньшей степенью вежливости. Сравним:

"Will you come upstairs, Dr. Watson, and inspect my collection of Lepidopter?" (Conan Doyle A. 'The Hound of the Baskervilles') [6].

"Will you remember to give them that message?" (Conan Doyle A. 'The Hound of the Baskervilles') [6].

В первом примере мы встречаемся с просьбойпредложением. Второй пример - это просьба, близкая к приказу.

При этом важно отметить, что вопросы c will you представляют собой достаточно прямое выражение просьбы, в то время как высказывания с would уоu носят более 
формальный характер, дистанцируя вопрошающего от своего собеседника:

"Well, would you please, sir, march upstairs, where we can get a cab to carry your highness to the police-station?"( Conan Doyle A. 'The Red-headed League') [6].

В качестве формул вежливого обращения, репрезентирующего просьбу, могут использоваться утвердительные конструкции с if, в которых принимают участие модальные глаголы:

"If you would have the great kindness to get rid of that sottish friend of yours I should be exceedingly glad to have a little talk with you." (Conan Doyle A. 'The Man with the Twisted Lip') [6].

Данный пример относится к так называемым развернутым высказываниям.

Итак, употребление предложений в сослагательном наклонении, которое репрезентируют желаемую ситуацию, придает высказыванию менее категоричный, а значит и более вежливый характер. Но мы также отметили, что этическая категория вежливости в грамматическом отношении может репрезентироваться через нетрадиционное использовании грамматических форм глагола. Так, например, для придания высказыванию вежливой формы довольно часто используются формы простого прошедшего, транспонированные в настоящее. Вопрос "Did you deduce the select?"( Conan Doyle A. 'The Adventure of the Noble Bachelor') [6] имеет более вежливый оттенок, чем вопрос "Do you deduce the select?"

Средством снижения прямолинейности просьбы, а, следовательно, и повышения степени вежливости высказывания, может служить также и употребление будущего времени вместо настоящего. Например:

"I shall want your help to-night." (Conan Doyle A. 'The Redheaded League') [6].

Употребление прошедшего или будущего времени вместо настоящего делает высказывание менее прямо- линейным. Происходит разрыв между действием, обозначенным в высказывании, и действительностью. В результате интенция говорящего теряет актуальность, а действие, к которому он побуждает, - обязательность исполнения.

В процессе данного исследования мы пришли к выводу, что в английском коммуникативном сознании вежливость является четко оформленным, хорошо структурированным речевым актом. Вежливые высказывания - это особый подкласс речевых единиц, объединяемый на основе общности функционирования, формы и содержания. Содержание категории вежливости определяется сложившимися в общественном сознании требованиями поведения, основной смысл которых заключается в выражении уважительности, почтительности и положительного отношения собеседников друг к другу. Однако как лингвистическая категория вежливость включает набор грамматических маркеров, представленных на морфологическом и синтаксическом уровнях.

На примере речевого акта просьбы мы выявили, что морфологическими средствами выражения вежливости являются: сослагательное наклонение, императив, формы прошедшего и будущего времени. Синтаксическими средствами выражения данной категории являются: вопросительные (вопросительно-утвердительные и вопросительно-отрицательные) конструкции (объектно-ориентированные и субъектно-ориентированные), а также утвердительные конструкции с if, в которых принимают участие модальные глаголы.

Как показало наше исследование, существуют прямые и косвенные способы репрезентации вежливости. Англичане предпочитают использовать косвенные способы, которые реализуются за счет грамматической формы сослагательного наклонения, вопросительных и отрицательных конструкций, а также модальных глаголов. Сослагательное наклонение чаще всего используется именно для реализации просьбы. Просьбы, при этом, получаются очень вежливыми и ненавязчивыми.

\section{ЛИТЕРАТУРА}

1. Егорова Ю.А. Сочетание вежливости и юмора как одна из особенностей британского речевого стереотипа // Сборник материалов международной конференции «Язык, культура, речевое общение», посвященный 85-летию проф. М.Я. Блоха. Часть І. - М.: Прометей, 2009. - С. 211-215.

2. Ерзинкян Е.Л. Лингвистическая категория вежливости: семантика и прагматика. - Ереван, Изд. ЕГУ, 2018. - 410 с.

3. Ларина Т.В. Категория вежливости и стиль коммуникации: Сопоставление английских и русских лингвокультурных традиций. - М.: Рукописные памятники Древней Руси, 2009. - 512 с.

4. Остин Дж. Л. Слово как действие // Новое в зарубежной лингвистике, вып. 17: Теория речевых актов. М.: Прогресс, 1986. - С. 22-129.

5. Christie Ch. // Journal of Politeness Research. - 2005. - Vol. 1 (1). - P. 1-7.

6. Conan Doyle A. The Complete Sherlock Holmes // URL: https://sherlock-holm.es/pdf/a4/1-sided.

7. Watts, R. Politeness. - Cambridge: CUP, 2003. - 304 p.

(c) Вендина Оксана Владимировна (oksya100@mail.ru), Ткаченко Анастасия Евгеньевна (anastasiiatkachenko@mail.ru), Филеши Ирина Владимировна (ir.mishencko@mail.ru).

Журнал «Современная наука: актуальные проблемы теории и практики» 